\title{
O ENSINO DE LITERATURA SOB O VIÉS DA LICENCIATURA
}

http://dx.doi.org/10.11606/issn.2237-1184.v0i24p114-124

Neide Luzia de Rezende

Universidade de São Paulo

RESUMO

O artigo busca aproximar, para problematizar, perspectivas diversas de ensino da literatura: a do curso de Letras e a do curso de Licenciatura da USP, tradicionalmente distanciados em relação às teorias e metodologias de ensino desse campo de saber. O curso de Letras forma especialistas de textos enquanto há décadas professores da Educação têm insistido na dimensão da recepção e do leitor.

\section{ABSTRACT}

This paper aims at analyzing the many perspectives literature is taught in the University of São Paulo: from Literature to Teacher's education. Both courses are traditionally different in theories and methodology about the literary text. While Literature undergraduate course has its focus on the formation of specialists, in the Faculty of Education professors have chosen the approach of reader's and reception theories.
PALAVRAS-CHAVE

Ensino de Literatura. Leitura Literária.

Letras.

Licenciatura.

\section{KEYWORDS}

Teaching of literature. Teacher's Education. Languages.

Literature.

\footnotetext{
${ }^{1}$ Docente da Faculdade de Educação da Universidade de São Paulo.
} 


\section{ntrodução}

Sempre se destacou na universidade a separação entre os cursos científicos (segundo a legislação, cursos de formação científico-cultural) e as licenciaturas (de formação didático- pedagógica), estas tradicionalmente consideradas como formação "menor" em relação aos outros, já que se volta para uma educação "inferior", a educação básica. Penso que essa ideia de menoridade influi subterraneamente no ensino oferecido na escola. Aqui, detenho-me na relação entre os cursos de Letras, da FFLCH, o curso de Licenciatura, da Faculdade de Educação, ambos da USP, e o Ensino Médio da rede pública, de São Paulo, tendo como objeto o ensino de literatura.

Bons conhecedores da constituição da língua e de sua literatura, entretanto conhecendo mal ou mesmo desconhecendo as metodologias e práticas escolares - uma vez que o curso de Letras tradicionalmente não oferece essa formação, e o de Licenciatura é curto, no geral, pouco valorizado -, a tendência é "aplicar" no ensino básico versões facilitadas do que se aprendeu na universidade 2 . Algo como uma "transposição didática" ${ }^{3}$, ou seja, verter para uma instância de ensino conteúdos criados e legitimados em outra, mas fazê-lo de um modo mais simplificado para que a matéria se torne apreensível para um público menos especializado.

Como analisou João Wanderley Geraldi, em livro de $1997^{4}$, esses conteúdos chegam ao professor da sala de aula de modo fetichizado, isto é, autonomizados, desvinculados de seu contexto de origem, ou das teorias em cujo interior se desenvolveram. Segundo ele, isso ocorre porque o professor foi se distanciando ao longo dos séculos das instâncias de produção do conhecimento, às quais tem acesso hoje por diferentes mediações, como cursos de licenciaturas, cursos organizados por

\footnotetext{
${ }^{2} \mathrm{O}$ esquema tradicional, vigente até bem pouco tempo, era baseado no modelo $3+1$ e supunha que o aluno fosse cursar um ano de disciplinas pedagógicas já praticamente no final do seu curso. Quer dizer, o estágio, as metodologias e outras disciplinas (no caso da FEUSP: Introdução à Educação, Didática, Políticas para a Educação Básica e Psicologia) eram apêndices de um curso de Letras voltado para especialistas da língua e da literatura. Na última década, com a implementação do Programa de Formação de Professores da USP e a redistribuição de horas de formação pedagógica entre as unidades, não apenas a cargo da faculdade de Educação, houve em determinado momento uma maior interação entre os diferentes cursos por força da constituição de uma comissão interunidades de licenciatura - já extinta pela pró-reitoria de Graduação -, estabelecendo-se algumas intenções mútuas de trabalho conjunto.

${ }^{3}$ A "transposição didática", assim denominada por Ives Chevallard (La transposition didactique : du savoir savant au savoir enseigné. Editions La Pensée Sauvage, 1998), tem sido problematizada ante a noção de "cultura escolar", na qual me deterei mais adiante.

${ }^{4}$ GERALDI, João W. "Identidades e especificidades do ensino de língua". Portos de Passagem. São Paulo: Martins Fontes, 1997.
} 
secretarias de educação, ou outros organismos educacionais, mas sobretudo pelos livros didáticos, que, ao fim e ao cabo, servem mais ao professor que ao aluno ${ }^{5}$. Tal situação faz com que o professor viva, como diz o autor, sob o signo da "desatualização", pois jamais conseguirá acompanhar as novidades científicas no ritmo em que elas se dão.

Mas ocorre também que, mesmo em princípio bem formado - como se espera de um aluno da USP, que aprende com professores pesquisadores, os quais supostamente têm sobre seus conteúdos de docência visão crítica e atualizada, além de propor perspectivas inovadoras advindas de pesquisas de sua área -, o então professor, recémformado, ao adentrar a escola, vê-se compelido, por força das condições de trabalho e da prática coletiva, a seguir determinado comportamento didático, desse modo excluindo novas abordagens que porventura tenha aprendido no curso de formação inicial, e sobretudo porque as novidades não foram acompanhadas da apropriação de uma metodologia de ensino para que tais conteúdos pudessem efetivamente fazer sentido a seus jovens alunos.

Na verdade, mantém-se na escola uma cultura que André Chervel denomina "cultura escolar", que não é mais um produto de conhecimento, mas uma tradição que foi sendo construída com conteúdos meio que "naturais da escola", e que tanto alunos quanto a sociedade reconhecem como sendo conteúdos escolares por excelência que devem ser dominados: na disciplina de Língua Portuguesa é o caso do ensino da gramática e da história da literatura. Nesta, este artigo pretende se deter.

\section{Uma crença na história da literatura como fator de humanização}

Há muito se sabe o que vem ocorrendo com o ensino de literatura na escola: o desaparecimento do texto literário, substituído por "simulacros" como já disseram Haquira Osakabe e Enid Yatsuda Frederico $^{7}$, num parecer ao MEC por ocasião da reformulação dos Parâmetros Curriculares do Ensino Médio (PCNEM), em 2006. Não obstante a insistência nesses documentos por mudança das práticas, tanto

\footnotetext{
${ }^{5}$ Pesquisas da área de educação indicam que a maioria dos professores da rede pública de ensino, no estado de São Paulo, pelo menos, são formados por institutos superiores particulares. Com poucas exceções, esses institutos não desenvolvem pesquisas, ou seja, não produzem conhecimento, mas o transmitem, o que podemos associar a que Bosi chama de "tendência especular", posição acrítica em relação ao conhecimento acumulado. (BOSI, Alfredo. "Culturas brasileiras". Dialética da colonização. São Paulo: Cia. das Letras, 1992)

${ }^{6}$ CHERVEL, A. "História das disciplinas escolares: reflexões sobre um campo de pesquisa". Teoria \& Educação, Porto Alegre, $n^{\circ}$ 2, p. 177-229, 1990.

7 OSAKABE, H.; FREDERICO, E. Y. "Literatura". Orientações curriculares do ensino médio. Brasília: MEC/ SEB/ DPPEM, 2004

${ }^{8}$ Os PCNEM de todas as áreas foram muito criticados, por isso novos documentos foram publicados em 2006, denominados Orientações Curriculares para o Ensino Médio (OCEM). Os pareceres também se fizeram públicos no site do MEC. Esta autora, junto com Enid Frederico Yatsuda e Maria Zélia Versiani Machado, foi uma das elaboradoras do documento.
} 
pesquisas quanto relatórios de estágio ${ }^{9}$ ainda revelam uma situação desonrosa para o ensino de literatura: essas fontes destacam não a recorrente cantilena de que o "aluno não lê", mas o fato de que as aulas não funcionam para tal conteúdo. Há um imenso hiato entre ensino e aprendizagem, que só tem se acentuado nos últimos vinte anos, período em que temos acompanhado diretamente a prática escolar ${ }^{10}$.

Talvez ancorado num ideal de formação, que considera a grande literatura capaz de devolver ao homem sua humanidade, o discurso sobre literatura na escola torna-se vazio de significado e profundamente tedioso, uma vez que, desvinculado da leitura literária, oferece apenas um aglomerado de dados sobre sua história. O artigo de Antonio Candido, "A literatura e a formação do homem", apresentado na SBPC em $1972^{11}$, incontornável quando se trata do assunto, enaltece a capacidade de humanização pela literatura, porém não deixa dúvidas de que isso só pode se firmar na vivência da literatura e não apenas no discurso sobre ela.

O que se percebe na escola, contudo, é a insistência na pregação da importância da grande literatura, como se daí irradiasse magicamente sua humanidade. Decerto, o professor não acredita nisso, mas profere o discurso como um mantra desolado - de resto fenômeno muito antigo este: "Já no século XIX, Lanson, o pai da história literária, lamentava que se ensinasse essa nova disciplina nos liceus uma vez que a maioria dos alunos não havia lido as obras cuja história aprendia"12 .

Há por parte dos formandos em Letras da USP uma obstinada crença na história da literatura ${ }^{13}$, como se essa história, linear e progressiva, que vai do século XIII ao século XX, fosse a única legítima, e que é só aí que se apresentam as possibilidades de entender os processos de ruptura e tradição da literatura ${ }^{14}$, e que qualquer outra alternativa estaria fadada a excluir a literatura da história... Decerto não é isso que ensinam os professores de Teoria Literária e Literatura Brasileira do curso de Letras da USP, mas, decerto, tocados por aquilo que trouxeram de sua recente trajetória pelo ensino médio, e que, afinal - creem - os tenha capacitado para entrar na universidade, não ousam desafiar o senso comum. Talvez se pensassem que a entrada nesse universo superior do curso de Letras só

\footnotetext{
${ }^{9}$ Refiro-me aqui aos milhares de relatórios produzidos pelos estudantes de licenciatura em Letras, na disciplina que ministro, Metodologia do Ensino de Língua Portuguesa, da Faculdade de Educação da USP, e nas pesquisas de mestrado e doutorado sobre o ensino de literatura, realizadas predominantemente nas escolas das redes pública e privada.

${ }^{10}$ A disciplina de Metodologia do Ensino de Língua Portuguesa (com dois semestres, Melp I e Melp 2) recebe, anualmente, cerca de 400 estudantes provenientes do curso de Letras, distribuídos em geral entre 7 a 8 turmas, sob a responsabilidade de 6 professores. A disciplina conjuga em carga horária de 150 horas semestrais, destas 90 horas correspondem a estágio.

11 CANDIDO, Antonio. "A literatura e a formação do homem". Remate de Males. Departamento de Teoria Literária/IEL/Unicamp, número especial Antonio Candido, Campinas, 1999.

12 VERRIER, Jean. "Vãs querelas e verdadeiros objetivos do ensino da literatura na França". Educação e Pesquisa, São Paulo, v.33, n.2, p. 207-213, maio/ago. 2007. p. 213

${ }^{13}$ Evidentemente, estou aqui generalizando, uma vez que, mesmo no interior de uma mesma formação educacional, as mentalidades não são homogêneas e, sim, há variedades de perspectivas, sobretudo geradas no interior dos movimentos culturais de gênero e étnico-raciais contemporâneos.

${ }^{14}$ A uma pergunta de Maria Thereza Fraga Rocco, no livro Literatura/ensino: uma problemática. (São Paulo: Ática, 1981. p. 156), Alfredo Bosi, um tanto reflexivamente responde que acha que se deveria ensinar literatura de um "certo moderno para trás"...
} 
foi possível devido a outras leituras realizadas fora da escola, e que talvez tenham sido elas e não o cânone que tenham aberto o caminho para a universidade...

\section{Uma velha nova história}

Desde a década de 1970, com intensidade na década de 80, várias autoras brasileiras têm escrito sobre a crise da literatura na escola, a maioria agrupadas no livro organizado por Regina Zilberman, A literatura em crise na escola: alternativas do professor ${ }^{15}$. Na USP, Ligia Chiappini Moraes Leite, do curso de Letras e professora de Teoria Literária, Maria Thereza F. Rocco e Alice Vieira, da Faculdade de Educação, investiram com vigor nos problemas do ensino de literatura na escola básica, em artigos e nas atividades acadêmico-profissionais (além da docência, nas elaborações de documentos públicos, em associações de professores, em ações no interior da Fuvest etc).

Ligia Chiappini foi professora de Teoria Literária de Letras-USP no período 1973-1997 e mediante inúmeras publicações (em especial na Linha d'Água, revista da APLL - Associação de Professores de Língua e Literatura, na qual atuou incessantemente), em projetos e coleções voltadas para professores ${ }^{16}$, apresenta uma visão crítica, já alinhada às novas perspectivas voltadas para o leitor que circulavam na Europa, em particular na França, onde fez seu estágio de pós-doutorado. Também orientou trabalhos de pós-graduação voltados para pesquisas da sala de aula e leituras dos jovens.

As professoras da FEUSP, Maria Thereza Fraga Rocco e Alice Vieira, elaboraram ambas estudos incisivos a esse respeito: Rocco publicou em 1981 o livro Literatura e ensino: uma problemática, sua dissertação de mestrado, defendida em 1975, para a qual entrevistou vários intelectuais da época, escritores, críticos, professores, sobre o ensino de literatura como era, quais os problemas, como deveria ser... Dentre os artigos que publicou sobre o tema, destaco em especial "Prazer e coerção no ensino de literatura" ${ }^{17}$, que assim se inicia: "Circular, viciosa e viciada é a situação do ensino de literatura no nosso $2^{\circ}$. Grau"; ali destaca aspectos críticos: o "dirigismo do livro didático e seu conteúdo invariável", o "programa fantasma" que é o de literatura; as "gincanas pedagógicas" que são os eventos de avaliação de estudos da literatura, e a história literária

\footnotetext{
${ }^{15}$ ZILBERMAN, Regina. Literatura em crise na escola: as alternativas do professor. Porto Alegre: Mercado Aberto, 1982.

${ }^{16} \mathrm{O}$ acervo do Projeto EFES - Estágio de Formação do Educador em Serviço que Ligia Chiappini desenvolveu junto a professores da rede pública do município e à secretaria de educação na gestão Paulo Freire encontra-se hoje sob minha responsabilidade na Faculdade de Educação e tem sido objeto de pesquisas no mestrado e iniciação científica.

${ }^{17}$ ROCCO, Maria Thereza F. "Prazer e coerção no ensino de literatura". Revista da Faculdade de Educação, n. 12, 1986, p. $77-84$
} 
como um "banco de dados e informações", desligado do contexto e voltado exclusivamente para o vestibular.

Alice Vieira, do mesmo modo, em sua tese de doutorado Análise de uma realidade escolar: o ensino de literatura no $2^{\circ}$ grau, hoje, defendida na FEUSP em 1988, considera três questões: "O que deve ser ensinado, segundo a Secretaria de Educação?; O que é ensinado, nas escolas da capital?; e $\mathrm{O}$ que é cobrado, ao término do $2^{\circ}$ grau, nos exames vestibulares?". Analisa a posição do governo estadual sobre o ensino de literatura mediante "reflexão sobre a Proposição Curricular de Lingua Portuguesa para o $2^{\circ}$ grau (1977) e seus Subsídios (1979), investiga o que efetivamente acontece nas salas de aula das escolas paulistanas por meio de pesquisa de campo desenvolvida a partir de questionários respondidos por professores e alunos do antigo segundo grau e se debruça sobre o que é cobrado nos exames vestibulares por meio da análise das questões sobre literatura do vestibular da Fuvest." 18 .

Uma questão comum e evidente de ambos os textos é a relação da literatura no ensino médio e o que é cobrado no vestibular da Fuvest, sendo que Rocco faz uma crítica veemente ao fato de o ensino médio só se preocupar com o vestibular. Anos depois, já no início de 2000, Maria Thereza ocupa um alto cargo dentro da Fuvest (vice-presidente) que lhe permite de algum modo interferir na orientação das provas. Embora, sob sua direção, permaneça a lista do cânone escolar (na ocasião justificava a exclusividade da lista canônica também pela dificuldade em obter direitos de publicação de autores mais contemporâneos), as questões das provas de literatura se distanciam da perspectiva historiográfica, ao não cobrar, ou cobrar menos, aspectos dos estilos de época, sustentando-se em tópicos que só a leitura das obras permitiria responder.

Evidencia-se, pois, nesse recorte estrito, circunstanciado na Universidade de São, mas mesmo assim significativo de pesquisa, teorias e militância, uma preocupação antiga de mais de trinta anos, com o ensino de literatura no ensino médio e uma crítica veemente à história literária desvinculada do contexto e avessa à participação do leitor, na sua dimensão coletiva de recepção.

Ademais, ao longo dos anos que se sucederam, voltamos insistentemente a pesquisas e artigos que versam sobre a mesma necessidade, mas que não reverberaram nas práticas escolares. O que nos leva a reconhecer a força da "cultura escolar" de que fala André Chervel, a qual que responde tanto aos interesses da escola quanto aos da sociedade. Constroi-se assim uma representação de práticas e conteúdos que permitem à escola funcionar segundo modos que se ajustam a uma tradição didática que lhe é propícia:

\footnotetext{
18 OLIVEIRA, Gabriela. R. As práticas de leitura literária de adolescentes e a escola: tensões e influências. Tese (Doutorado em Educação). Faculdade de Educação, USP, 2013. p. 63
} 
1. resolve o problema da seleção de obras, pois constitui um corpus definido e nacionalmente instituído, mas elimina as peculiaridades regionais; 2 . resolve o problema da falta de preparação e de conhecimento literário que possa existir entre os professores, já que esses lidam com a reprodução de uma crítica institucionalizada, porém esse procedimento impede $\mathrm{o}$ professor de ser ele próprio um leitor crítico e estabelecer suas próprias hipóteses de leitura para abraçar as investidas mais livres de seus alunos na leitura; 3. permite cobrir um tempo extenso, numa linha que vai do século XII ao século XXI, destacando momentos reconhecidos da tradição literária, porém tal extensão torna-se matéria para simplesmente decorar, e características barrocas, românticas, naturalistas, etc. confundem-se freneticamente, sem nada ensinar; 4 . permite tomar conhecimento de um grande número de títulos e autores, mas, em virtude da quantidade e variedade, a leitura do livro é inviabilizada e entendida como secundária; e 5. permite ao aluno o reconhecimento de características comuns a um grande número de obras, porém obriga a obra a se ajustar às peculiaridades da crítica e não o contrário. ${ }^{19}$

Ou seja, as adversativas neste trecho, deixadas de lado - por não caberem como conteúdo, uma vez que a cobertura do "programa fantasma" as inviabilizaria -, são, justamente, a parte que se reivindica hoje para um ensino/aprendizagem mais consistente da literatura no ensino médio no Brasil ${ }^{20}$.

\section{O ensino de literatura para a educação básica no curso de Letras}

Por outro lado, observa-se que na formação dos alunos de Letras, até muito recentemente, encontrava-se ausente a perspectiva das metodologias para o ensino básico ${ }^{21}$. A experiência levada a cabo por Ligia Chiappini nas décadas de 80 e $90^{22}$ deixaram poucos rastros, tanto que o acervo do EFES encontrou seu lugar na Faculdade de Educação ${ }^{23}$. E aí volto ao início deste texto, para qualificar mais uma vez de "menor" a questão do ensino básico no curso do Letras, voltado exclusivamente para o texto literário, de modo a criar especialistas de textos e de autores, o que em grande parte leva seus estudantes, futuros professores, a desdenharem

\footnotetext{
${ }^{19}$ BRASIL. "Conhecimentos de Literatura". Orientações Curriculares para o Ensino Médio. Brasília: SEB, Ministério da Educação, 2006. p. 76

20 São muitos os pesquisadores que corremos o país oferecendo simpósios e ministrando palestras nos eventos da área para divulgar um novo projeto de literatura na escola. Cito apenas alguns, mas a lista tem felizmente aumentado: Vera Teixeira de Aguiar, Regina Zilbermann, Hélder Pinheiro, Cyana Leahy-Dios, Benedito Antunes, Ana Crélia Dias, Maria Amélia Dalvi, Vima Lia Rossi Martin, Gabriela Rodella de Oliveira, Robson Coelho Tinoco, Ricardo Chacón, Rita Jover-Faleiros etc.

${ }^{21}$ Depois do Programa de Formação de Professores, algumas disciplinas de literatura comparada, optativas têm abordado a questão.

22 Junto com Adilson Citelli, coordenou uma importante coleção da editora Cortez, Aprender e ensinar com textos, cujos três primeiros livros foram fruto do projeto junto aos professores da rede municipal de São Paulo.

23 Diante disso, é louvável o esforço de Andrea Hossne, do Departamento de Teoria Literária e Literatura Comparada, da FFLCH-USP, e equipe, com a organização semestral, desde 2016, da Jornada de Leitores e Leituras na Contemporaneidade, a qual vem incorporando participações que abrem um leque de contribuições práticas e teóricas para o ensino básico.
} 
de outras possíveis leituras que não as dos críticos - o que explica também o "ensino de literatura", ou o ensino do texto, presente na cultura escolar, ou seja, ensinar alunos a reconhecer nos textos da tradição aquilo que a crítica especializada disse a respeito deles, considerando ilegítimos possíveis sentidos que o aluno possa extrair, ou aproximações com textos da cultura contemporânea que componham a leitura dos jovens (esta sim uma grande heresia, do ponto de vista dos defensores da exclusividade do cânone na escola).

Discutir o deslizamento de sentido de "ensino de literatura" para "leitura literária" ajuda a entender a perspectiva da Educação e o movimento que aqui se faz em direção ao curso de Letras.

\section{A questão da leitura literária}

A noção de "leitura literária", recorrente hoje nos discursos sobre o ensino de literatura, tanto em documentos oficiais, quanto em artigos, chamadas de eventos e nas falas dos professores, em lugar do tradicional "ensino de literatura", introduz um elemento que, a nosso ver, não tem sido percebido em essência: recuperar o ensino de literatura pelo viés da leitura literária é, evidentemente, pensar no leitor, o que introduz uma alteração fundamental, com potencial de grandes transformações no currículo, uma vez que poderia interferir no ritmo das tarefas escolares, as quais tradicionalmente precisam de velocidade para cobrir o amplo conjunto de conteúdos. Ao mesmo tempo, ter o leitor como instância da literatura requer um esforço teórico e metodológico considerável, por ser um novo ângulo de observação da realidade. Como diz Geraldi:

Pontos de vista muito mais amplos contribuem na definição de como se vê o fenômeno a descrever e explicar através do modelo ou idealização do cientista. Isto significa, de um lado, que os produtos de um trabalho científico têm que ser vistos com desconfiança crítica e, por outro lado, que as disputas na definição do objeto, do que lhe é próprio e do que lhe é exterior, produzem resíduos, recuperáveis a partir de outros postos de observação. Neste sentido, as flutuações nos projetos de conhecimento, os processos de construção e desconstrução jamais permitirão que, neste terreno, se coloque o ponto final. O estado provisório das opções garantirá um movimento contínuo, pois não se trata de uma caminhada teleológica em busca da estabilidade na terra prometida: ponto fixo. Neste processo de construção e desconstrução faz- se a história da ciência. ${ }^{24}$

Em geral, essas novas teorias sobre a leitura literária têm apontado para o cuidado com aquele que aprende e não apenas com aquilo que se ensina, tanto que ao termo "ensino" associou-se o de "aprendizagem", num binômio inseparável.

${ }^{24}$ GERALDI, João W. Portos de Passagem, 1997, p. 73. 
Desde o início da década de 60, a discussão sobre a História da Literatura se mostra intensa nos países europeus e tem se irradiado para outros continentes ${ }^{25}$. Destaco três textos: um de 1961, de Hans Robert Jauss, "A história da literatura como provocação à história da literatura", e outros dois, de Roland Barthes, "História ou literatura?", de 1963, e "A morte do autor", de 1968.

O de Jauss, nascido de uma conferência e de um trabalho de alguns professores - dentre os quais, o famoso entre nós Wolfgang Iser - da Escola de Constança, na Alemanha ${ }^{26}$, critica duas perspectivas teóricas muito influentes na época: o formalismo e o marxismo, mostrando as fragilidades de ambas e como nenhuma das duas inclui a recepção no horizonte da literatura, sendo essa recepção o que define o movimento do cânone e as respostas à produção literária. Jauss inclui o leitor como instância da literatura ${ }^{27}$. Por sua vez, Barthes, no primeiro ensaio acima citado, problematiza o modo como se apresenta a história da literatura, que não é história nem literatura: "de história só tem o nome: é uma sequência de monografias, cada uma das quais, com poucas diferenças, delimita um autor e o estuda por ele mesmo; nesse caso, a história é apenas uma sucessão de indivíduos"28. E conclui, em "A morte do autor": "sabemos que, para devolver à escritura o seu futuro, é preciso inverter o mito: o nascimento do leitor deve pagar-se com a morte do Autor."29

Lembro-me de que, durante a graduação, nos idos da década de 80, após termos lido - e mal entendido o que Barthes propunha neste texto, uma vez que a problemática do ensino de literatura na escola passava longe de nossas preocupações - faziam-se brincadeiras com a "morte do autor", compreendendo de modo enviesado e fora de contexto suas ideias, o que lembra o conceito de fetichização abordado por Geraldi.

Essas discussões dos anos 60 representam, pois, uma intervenção importante no ensino de literatura, que aqui no Brasil só começaram a se fazer presentes do ponto de vista teórico nos anos 80, como apontamos, com um movimento liderado pelas autoras aqui mobilizadas. Interessante observar que nesses anos de 1980, as propostas curriculares do estado de São Paulo, publicadas em fascículos verdes - os "verdões" - traziam muitas e excelentes contribuições didáticas dos professores da USP, mas todas voltadas para a análise de textos.

\footnotetext{
${ }^{25} \mathrm{Na}$ América Latina, por exemplo, os sistemas de ensino adotam diferentes perspectivas para o ensino da literatura, no que são acompanhados pelos livros didáticos. Na Argentina, por exemplo, os textos literários são potencializados por bons estudos críticos e pela necessidade de reconhecer uma "identidade nacional".

${ }^{26}$ Este texto de Jauss foi trazido por Regina Zilberman no seu Estética da Recepção e história da literatura, de 1989, publicado pela Editora Ática.

${ }^{27}$ JAUSS, Hans Robert. A história da literatura como provocação à teoria literária. Trad. Sérgio Tellaroli. São Paulo: Ática, 1994.

${ }^{28}$ BARTHES, Roland. Sobre Racine. Tradução: Ivone C. Benedetti. São Paulo: Martins Fontes, 2008 História ou literatura? p. 187

${ }^{29}$ BARTHES, Roland. "A morte do autor". O rumor da língua. Trad. Mario Laranjeira. São Paulo: Brasiliense, 1988. p.70.
} 
Assim, continua a escola pública a solicitar de seus alunos uma pesquisa de autores e de suas obras na internet...

\section{Divórcio entre oferta pedagógica e práticas sociais dos estudantes}

Observamos hoje uma diversidade extraordinária de culturas na escola. Se, por um lado, temos essa cultura escolar naturalizada, por outro, temos outras, as dos alunos, que são invisíveis para a escola.

Crianças e jovens vivenciam hoje uma situação de sociabilidade e comunicação absolutamente extraordinária; jamais tiveram o acesso livre e autônomo que agora têm (para o bem e para o mal) quanto à inserção na cultura, mediante as redes sociais. Do mesmo modo, os professores têm pertencimentos culturais os mais distintos e também são agora marcados pelos meios digitais. Assim, práticas sociais democráticas aproximam jovens de distintas culturas e abrem para múltiplos tipos de informação e saber. Como adverte Max Butlen:

As novas tecnologias oferecem ferramentas extraordinárias para construir os saberes, sem dúvida. Mas é possível também que sejamos vítimas de novas ilusões como foi o caso anterior quando da aparição do audiovisual. A ferramenta é uma coisa, o domínio da mesma é outra coisa, a introdução e a inclusão dessa inovação na sala de aula é, por sua vez, uma terceira coisa. Dispor de milhares de informações na web não implica automaticamente a apropriação delas. A localização, o tratamento, a análise, os usos das fontes de informação demandam uma aprendizagem complicada e requerem professores capazes de acompanhar esse percurso. ${ }^{30}$

Há jovens, egressos do ensino médio, que compõem raps bem construídos, participam de slams mas que nunca ouviram falar de Manuel Bandeira ou jamais leram Carlos Drummond de Andrade. São estéticas que surgiram no âmbito da cultura marginal-periférica, do universo da cultura popular contemporânea, e que são invisíveis e ilegítimas para a escola, uma vez que o que vale é a literatura impressa, em papel: "estamos diante de um fenômeno relacionado ao divórcio entre a oferta pedagógica e a recepção por parte dos leitores adolescentes", como lembra mais uma vez Max Butlen ${ }^{31}$.

Ora, não quer dizer que agora a escola deveria ensinar isso aos alunos, comentário que ouço com frequência dos estudantes na licenciatura. A escola não precisa ensinar isso, isso os alunos já conhecem, o que a escola pode fazer - e deveria - é, de repente, rever o seu papel de transmissora de conhecimento, e abrir-se para possibilidades mais complexas e instigantes, afinal, afastar-se do "programa fantasma", e, a

\footnotetext{
${ }^{30}$ BUENO, Belmira; REZENDE, Neide L. "Formador de leitores, formador de professores: a trajetória de Max Butlen". Educação e Pesquisa, São Paulo, v. 41, n. 02, p. 543-564, abr./jun. 2015. p. 561

${ }^{31}$ Idem. P. 559.
} 
partir do que os alunos já conhecem (como, de resto, proferiu há muito o construtivismo), investir em práticas de reflexão e de crítica. Tanto a leitura quanto a escrita são atividades que necessitam de tempo, seja para elaboração das ideias do outro quanto as de si próprio.

\section{Por fim...}

Necessário deixar claro mais uma vez que o universo abordado neste artigo se atém à Universidade de São Paulo, do curso de Letras da FFLCH, e à Licenciatura em Letras da Faculdade de Educação, especificamente no âmbito da disciplina Metodologia do Ensino de Língua Portuguesa, uma vez que há grande diversidade hoje na composição dos cursos de Letras e de Licenciatura em Letras, sobretudo com o aumento das universidades federais no período de 2002 a 2014, e com as novas diretrizes do MEC para os cursos superiores durante esse período.

A profissionalização dos bacharéis em Letras, em especial os formados em Língua Portuguesa, na sua especificidade, aparentemente não é muito extensa - concentrada principalmente em revisores de texto (com trabalhos na sua maioria informais e não muito bem pagos), os egressos também se dispersam em outras funções, como editores, críticos literários, jornalistas etc.

É natural que com tantos formandos ${ }^{32}$ e com um campo reduzido de trabalho, a docência seja uma perspectiva (alternativa?) bastante provável, mais sedutora na rede particular do que na rede pública, já que esta não oferece uma carreira promissora de verdade, em razão das condições ruins de trabalho e dos baixos salários. Essas condições não tornam a profissão de professor de ensino público efetivamente respeitável para os egressos do curso de Letras, tornando-a desprestigiada e, consequentemente, desvalorizada nos seus contornos, daí o sentimento de menoridade em relação aos conteúdos e práticas.

${ }^{32}$ Em 2015, o número de estudantes ativos no curso de Letras era de 4.830, mais do que o triplo do segundo curso da FFLCH com mais números de alunos. Site: http://graduacao.fflch.usp.br/node/121. Acessado em 7/12/2017. 